\title{
Thermal Stability of W-Contacted Junction Diodes
}

\author{
Wen-Kuan Yeh, Kuang-Yang Chan, Ting-Chang Chang, and Mao-Chieh Chen* \\ Department of Electronics Engineering, National Chiao Tung University and National Nano Device Laboratory, \\ Hsinchu, Taiwan
}

Mou-Shiung Lin

Taiwan Semiconductor Manufacturing Company, Hsinchu, Taiwan

\begin{abstract}
This work investigates the thermal stability of $\mathrm{W}$-contacted $\mathrm{p}^{+} \mathrm{n}$ junction diodes, in which the tungsten contact was formed by selective chemical vapor deposition (CVD) or sputtering process. Reaction of Al and CVD-W at elevated temperature leads to the formation of $\mathrm{WAl}_{12}$, and the barrier capability of CVD-W film was dependent on the consumption of $\mathrm{W}$. The sputter-W film has a columnar structure and contains a higher content of oxygen. The presence of oxygen retarded the formation of $\mathrm{WAl}_{12}$ and thus enhanced the thermal stability of the $\mathrm{Al} / \mathrm{W} / \mathrm{Si}$ structure. However, degradation of the $\mathrm{Al} / \mathrm{sputter}-\mathrm{W}(100 \mathrm{~nm}) / \mathrm{p}^{+} \mathrm{n}$ diodes occurred after $30 \mathrm{~min}$ annealing at $550^{\circ} \mathrm{C}$, presumably due to $\mathrm{Al}$ diffusion along the grain boundary of sputter-W film. For the CVD-W contacted junction diodes, insertion of a thin TiN barrier layer between the $\mathrm{Al}$ and $\mathrm{W}$ film was effective in suppressing the formation of $\mathrm{WAl}_{12}$ and thus improved the device's thermal stability.
\end{abstract}

\section{Introduction}

In very large scale integrated (VLSI) process technology, fabrication of highly reliable low contact resistance shallow junctions is of great concern. Thus, the introduction of barrier layers between the aluminum metallization and the silicon substrate is becoming increasingly important in order to avoid junction spiking and contact degradation caused by the transport of substrate silicion into the aluminum overlayer. ${ }^{1}$ Tungsten is considered to be a good contact barrier to protect shallow junctions from aluminum spiking ${ }^{2,3}$ and preserve low contact resistance. ${ }^{4,5}$ However, formation of W-Al alloy, such as $\mathrm{WAl}_{12}{ }^{6,7} \mathrm{WAl}_{5}{ }^{8}$ or $\mathrm{WAl}_{4},{ }^{9}$ was reported for the $450^{\circ} \mathrm{C}$ annealed $\mathrm{Al} / \mathrm{W} / \mathrm{Si}$ structure, and interdiffusion between $\mathrm{Al}$ and $\mathrm{Si}$ substrate after $500^{\circ} \mathrm{C}$ annealing was reported. ${ }^{10}$ Nonetheless, little study has been made on the $\mathrm{Al} / \mathrm{W} / \mathrm{p}^{+} \mathrm{n}$ junction diode with regard to electrical characteristics of the thermal aspects. This work investigates the thermal stability of $\mathrm{W}$ contacted $\mathrm{p}^{+} \mathrm{n}$ junction diodes in which the $\mathrm{W}$ contact was formed by selective CVD as well as sputtering process. Furthermore, the effect of an additional thin TiN layer as a diffusion barrier was also investigated.

\section{Experimental}

The starting material was n-type $<100>$ oriented Si wafers with 10 to $20 \Omega$-cm nominal resistivity. After RCA standard cleaning, the wafers were thermally oxidized to grow a 4000 $\AA$ oxide layer. Diffusion areas with a size of $100 \times 100 \mu \mathrm{m}$ were defined on the oxide-covered wafers using the conventional photolithographic technique. The $\mathrm{p}^{+} \mathrm{n}$ junctions were formed by $\mathrm{BF}_{2}^{+}$implantation at $30 \mathrm{keV}$ to a dose of 3 $\times 10^{15} \mathrm{~cm}^{-2}$ followed by furnace annealing at $900^{\circ} \mathrm{C}$ for 30 min in $\mathrm{N}_{2}$ ambient. A $4000 \AA$ of tetraethylorthosilicate (TEOS) layer was then deposited on the wafers, and contact holes with sizes ranging from 1.2 to $3 \mu \mathrm{m}$ were defined using the conventional photolithographic technique, such that each diffusion region (with an area of $100 \times 100 \mu \mathrm{m}$ ) contains a total of 25 contacts. The wafers were split into four groups for the preparation of the following $W$ contacted junction diodes: sputter-W/p ${ }^{+} n, C V D-W \quad(100$ $\mathrm{nm}) / \mathrm{p}^{+} \mathrm{n}, \mathrm{CVD}-\mathrm{W}(300 \mathrm{~nm}) / \mathrm{p}^{+} \mathrm{n}$, and TiN/CVD-W $(300$ $\mathrm{nm}) / \mathrm{p}^{+} \mathrm{n}$. The sputter-W film was deposited using dc magnetron sputtering in $\mathrm{Ar}$ ambient at a pressure of $8 \mathrm{mTorr}$ and with a deposition a rate of $3 \mathrm{~nm} / \mathrm{min}$. The CVD-W films were deposited using the selective CVD-W technique with the process of silane reduction of $\mathrm{WF}_{6}$ conducted with conditions illustrated as follows: substrate temperature

* Electrochemical Society Active Member. $300^{\circ} \mathrm{C}$, total gas pressure 0.1 Torr, $\mathrm{WF}_{6}$ flow rate $20 \mathrm{sccm}$, $\mathrm{SiH}_{4}$ flow rate $10 \mathrm{sccm}$, and $\mathrm{H}_{2}$ carrier gas flow rate 1000 sccm. The CVD-W films of two different thicknesses, 100 and $300 \mathrm{~nm}$, were deposited. Part of the samples with 300 $\mathrm{nm}$ CVD-W films were further deposited with a $40 \mathrm{~nm}$ of TiN layer; the TiN deposition was carried out by reactive sputtering a pure Ti target in mixed $\mathrm{Ar} / \mathrm{N}_{2}(7 / 1)$ ambient at a pressure of $5 \mathrm{~m}$ Torr. Finally, $\mathrm{Al}$ metallization was applied to all samples, followed by $30 \mathrm{~min}$ sintering at $400^{\circ} \mathrm{C}$. For the thermal stability study of the diodes, the samples were thermally annealed in $\mathrm{N}_{2}$ flowing furnace for $30 \mathrm{~min}$ at a temperature ranging from 400 to $600^{\circ} \mathrm{C}$. Contact resistance of the junction diodes was measured using the four-terminal Kelvin structure. X-ray diffraction (XRD) analysis was used for crystalline-phase identification. Scanning electron microscopy (SEM) was employed to inspect the change of microstrcture, and secondary ion mass spectroscopy (SIMS) was used to measure the depth profile of atomical composition. The x-ray photoelectron spectroscopy (XPS) was used to analyze the $\mathrm{Al} / \mathrm{W}$ interface.

\section{Results and Discussion}

Figure 1 shows the statistical distributions of reverse bias leakage currents for four different structures of $\mathrm{W}$ contacted $\mathrm{p}^{+} \mathrm{n}$ junction diodes annealed at various temperatures. The junction characteristics of the Al/CVD-W (300 $\mathrm{nm}) / \mathrm{p}^{+} \mathrm{n}$ junction diodes were stable up to $550^{\circ} \mathrm{C}\left(\mathrm{Fig} .1 \mathrm{c}_{3}\right)$, while those of the Al/CVD-W $(100 \mathrm{~nm}) / \mathrm{p}^{+} \mathrm{n}$ and $\mathrm{Al} / \mathrm{sput-}$ tered-W $(100 \mathrm{~nm}) / \mathrm{p}^{+} \mathrm{n}$ junction diodes were severely degraded (Fig. $1 a_{4}$ and $1 b_{3}$ ). It is clear that the thermal stability of the Al/CVD-W/ $/ \mathrm{p}^{+} \mathrm{n}$ diodes was substantially improved by using a thicker $\mathrm{W}$ film. In addition, insertion of a TiN layer between $\mathrm{Al}$ and $\mathrm{W}$ further improved the diode's thermal stability and a majority of the Al/TiN/CVD-W $(300 \mathrm{~nm}) / \mathrm{p}^{+} \mathrm{n}$ diodes $(>50 \%)$ remained stable up to $600^{\circ} \mathrm{C}$ (Fig. $1 \mathrm{~d}_{4}$ ). The degradation of the Al/CVD$\mathrm{W} / \mathrm{p}^{+} \mathrm{n}$ junction diodes was due to the interdiffusion between $\mathrm{Al}$ and $\mathrm{Si}$ (which was confirmed later in Fig. 8), but the formation of $\mathrm{WAl}_{12}$ retarded the diffusion of $\mathrm{Al}$ until the $\mathrm{W}$ layer was entirely consumed. The $\mathrm{x}$-ray diffraction patterns for the Al/CVD-W/Si samples are illustrated in Fig. 2 and 3. For the Al/CVD-W (100 nm)/Si sample, the $\mathrm{WAl}_{12}$ signal appeared after $500^{\circ} \mathrm{C}$ annealing, and was accompanied by the diminution of the $\alpha-W$ signal. After $550^{\circ} \mathrm{C}$ annealing, the $\mathrm{W}$ signal further weakened, while various signals of $\mathrm{WSi}_{2}$ phase appeared. For the $\mathrm{Al} / \mathrm{CVD}-\mathrm{W}(300 \mathrm{~nm}) / \mathrm{Si}$ sample, weak signals fo the $\mathrm{WAl}_{12}$ phase were found after $575^{\circ} \mathrm{C}$ annealing. It was presumed 


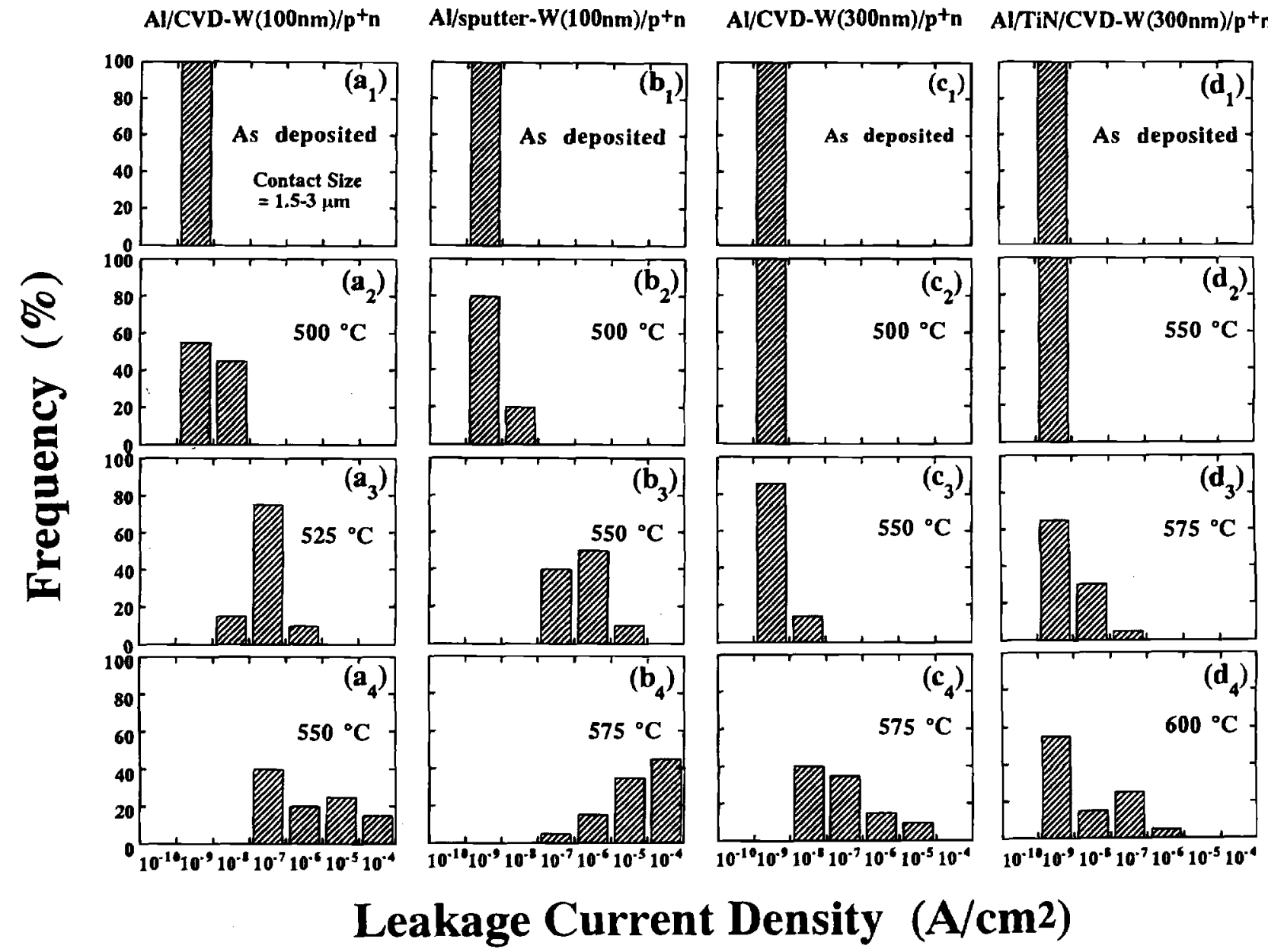

Fig. 1. Histograms showing the distribution of reverse leakage current density measured at $-5 \mathrm{~V}$ for (a) Al/CVD-W (100 nm)/p $\mathrm{n}^{+}(\mathrm{b})$ Al $/$ sputter-W (100 nm)/p $n$, (c) Al/CVD-W $(300 \mathrm{~nm}) / \mathrm{p}^{+} \mathrm{n}$, and (d) Al/TiN $(40 \mathrm{~nm}) / \mathrm{CVD}-\mathrm{W}(300 \mathrm{~nm}) / \mathrm{p}^{+} \mathrm{n}$ junction diodes annealed at various temperahures.

that the thin $\mathrm{W}$ film of $100 \mathrm{~nm}$ was almost entirely consumed by the formation of $\mathrm{WAl}_{12}$ after the $550^{\circ} \mathrm{C}$ anneal leading to severe junction degradation of the $\mathrm{Al} / \mathrm{CVD}-\mathrm{W}$ $(100 \mathrm{~nm}) / \mathrm{p}^{+} \mathrm{n}$ diodes due to $\mathrm{Al}$ duffusion into the Si substrate. For the $\mathrm{W}$ film of $300 \mathrm{~nm}$ thickness, part of the $\mathrm{W}$ layer was converted into $\mathrm{WAl}_{12}$ after the $550^{\circ} \mathrm{C}$ anneal for $30 \mathrm{~min}$; thus, electrical characteristics of the $\mathrm{Al} / \mathrm{CVD}-\mathrm{W}$ $(300 \mathrm{~nm}) / \mathrm{p}^{+} \mathrm{n}$ diodes basically remained stable up to $550^{\circ} \mathrm{C}$. Figure 4 shows the $\mathrm{x}$-ray diffraction patterns of the $\mathrm{Al} /$ sputter-W $(100 \mathrm{~nm}) / \mathrm{Si}$ sample, in which the $\beta-\mathrm{W}$ and the broadened $\alpha-\mathrm{W}$ peaks were observed. In contrast with the sample composed of sputter-W; instead it appeared after $575^{\circ} \mathrm{C}$ annealing. Apparently, the formation of $\mathrm{WAl}_{12}$ was retarded for the sputter-W film. Figure 5 shows the cross section and top view SEM micrographs for the four different $\mathrm{W}$ contacted multilayer structures after $550^{\circ} \mathrm{C}$ annealing. It is shown that most of the $100 \mathrm{~nm}$ CVD-W film was consumed to form the $\mathrm{WAl}_{12}$ compound and thus its barrier capability was lost against $\mathrm{Al}$ diffusion (Fig. $5 \mathbf{a}_{1}$ and $5 a_{2}$ ). The columnar structure of the sputter-W film (Fig. $5 \mathrm{~b}_{2}$ ) belongs to $\beta$-type $\mathrm{W}$ structure, ${ }^{11}$ which contains a large number of grain boundaries; the grain boundary acts as a diffusion path of $\mathrm{Al}$ into the Si substrate. Many pinholes can be seen on the surface of the Al/sputter-W/Si sample (Fig. $5 b_{1}$ ), though the sputter-W/Si interface looked nearly unchanged. Thus, for the $\mathrm{Al} / \mathrm{sputter}-\mathrm{W} / \mathrm{p}^{+} \mathrm{n}$ diodes, it is presumed that the degradation of junction was due to $\mathrm{Al}$ diffusion along the grain boundary of sputter-W film into the $\mathrm{Si}$ substrate. The Al/CVD-W $(300 \mathrm{~nm}) / \mathrm{Si}$ samples did not degrade after $550^{\circ} \mathrm{C}$ anneal because the thicker $\mathrm{W}$ film was only partially consumed and the W/Si interface remained unchanged (Fig. $5 c_{1}$ and $5 c_{2}$ ). With the insertion of a TiN layer between $\mathrm{Al}$ and $\mathrm{W}$, it was possible to suppress the $\mathrm{WAl}_{12}$ compound formation, keeping the $\mathrm{W} / \mathrm{Si}$ interface as well as the Al surface unchanged up to $550^{\circ} \mathrm{C}$ (Fig. $5 \mathrm{~d}_{1}$ and $5 \mathrm{~d}_{2}$ ).

Figure 6 shows the increase of sheet resistance for the various $W$ contacted structures as a function of annealing temperature. Below $450^{\circ} \mathrm{C}$, all samples remained stable. At $500^{\circ} \mathrm{C}$, sheet resistance of the $\mathrm{Al} / \mathrm{CVD}-\mathrm{W}(100 \mathrm{~nm}) / \mathrm{Si}$ sample revealed a drastic increase, while that of the other samples still remained fairly stable. Slight degradation was observed for the $\mathrm{Al} / \mathrm{sputter}-\mathrm{W}(100 \mathrm{~nm}) / \mathrm{Si}$ sample at $550^{\circ} \mathrm{C}$, while sheet resistance of the Al/TiN/CVD-W $(300$ $\mathrm{nm}) /$ Si sample basically remained stable. The increase of sheet resistance may relfect the consumption of conductive aluminum due to the formation of $\mathrm{WAl}_{12}$. For the $\mathrm{Al} / \mathrm{CVD}-\mathrm{W}(100 \mathrm{~nm}) / \mathrm{Si}$ sample, the $\mathrm{WAl}_{12}$ compound was formed after the $500^{\circ} \mathrm{C}$ anneal leading to the increase of sheet resistance. After the $550^{\circ} \mathrm{C}$ anneal, the thin CVD-W was largely consumed resulting in mass transport of $\mathrm{Al}$ in $\mathrm{Si}$, which can be understood from Fig. 8 shown later in this section; thus, sheet resistance of the sample further increased drastically. For the Al/CVD-W (300 nm)/Si sample, the increase of sheet resistance was due only to the formation of $\mathrm{WAl}_{12}$. For the Al/sputter-W/Si sample, higher oxygen content in the sputter-W film (which was confirmed and is shown in Fig. 7) retarded the formation of 


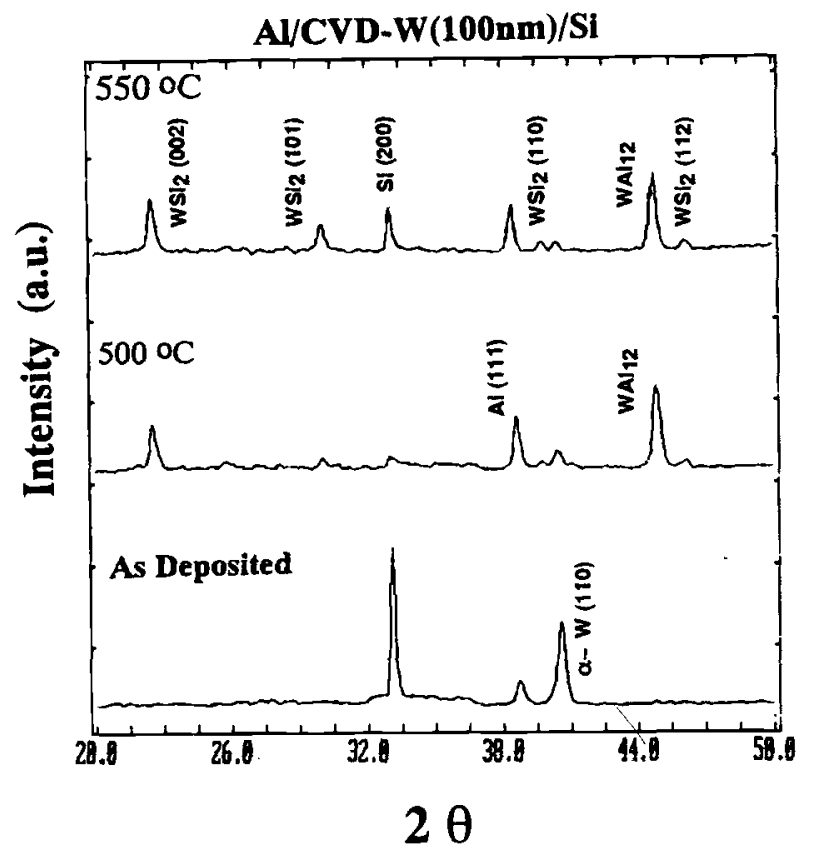

Fig. 2. XRD spectra of Al/CVD-W $(100 \mathrm{~nm}) / \mathrm{Si}$ sample before and after thermal annealing.

$\mathrm{WAl}_{12} ;$ the slight increase of sheet resistance after the $550^{\circ} \mathrm{C}$ anneal was presumably due to the formation of $\mathrm{WAl}_{12}$ as well as aluminum oxide. Figure 7 shows the results of XPS analysis for the $550^{\circ} \mathrm{C}$ annealed $\mathrm{Al} /$ sputter$\mathrm{W} / \mathrm{Si}$ and $\mathrm{Al} / \mathrm{CVD}-\mathrm{W} / \mathrm{Si}$ samples with respect to the $\mathrm{O}_{1 \mathrm{~s}}$, $\mathrm{W}_{4 \mathrm{f}}$, and $\mathrm{Al}_{2 \mathrm{p}}$ spectra. Each spectrum was taken after $2 \mathrm{~min}$ of $\mathrm{Ar}^{+}$ion milling to pre-etch the $\mathrm{Al}$ surface, which corresponds to a removal of about $20 \mathrm{~nm} \mathrm{Al} \mathrm{from} \mathrm{the} \mathrm{surface.} \mathrm{In}$ this work, the total sputtering time was $10 \mathrm{~min}$, when the ion reached the $\mathrm{Al} / \mathrm{W}$ interface. For the $\mathrm{Al} / \mathrm{sputter}-\mathrm{W} / \mathrm{Si}$ samples, $O_{s}$ peak [binding energy (B.E.) $=532.14 \mathrm{eV}$ ]

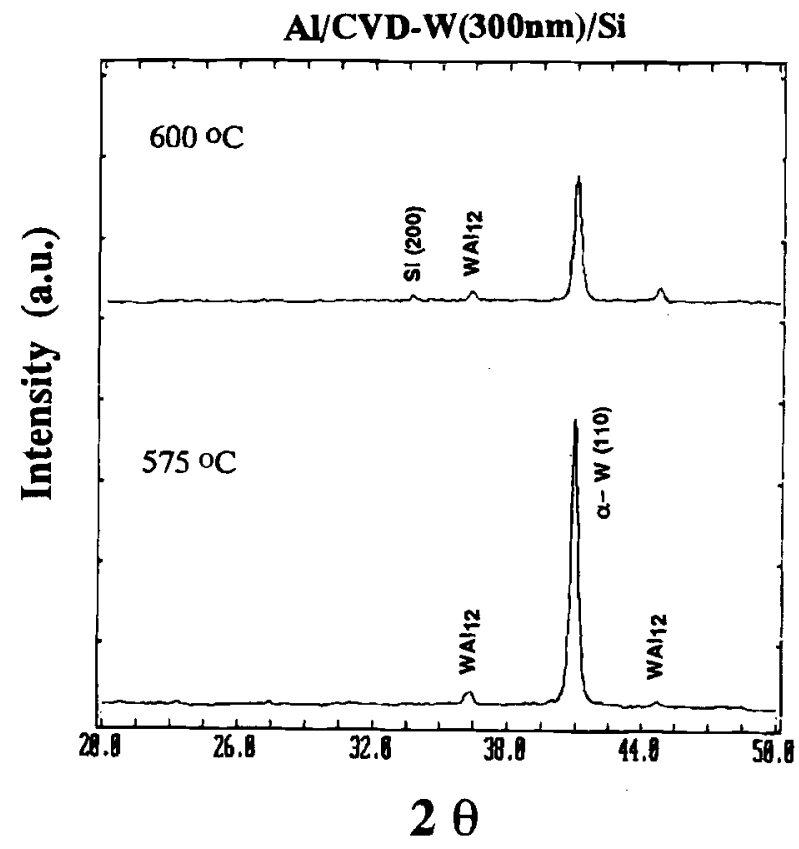

Fig. 3. XRD spectra of Al/CVD-W $(300 \mathrm{~nm}) / \mathrm{Si}$ sample before and ofter thermal annealing.

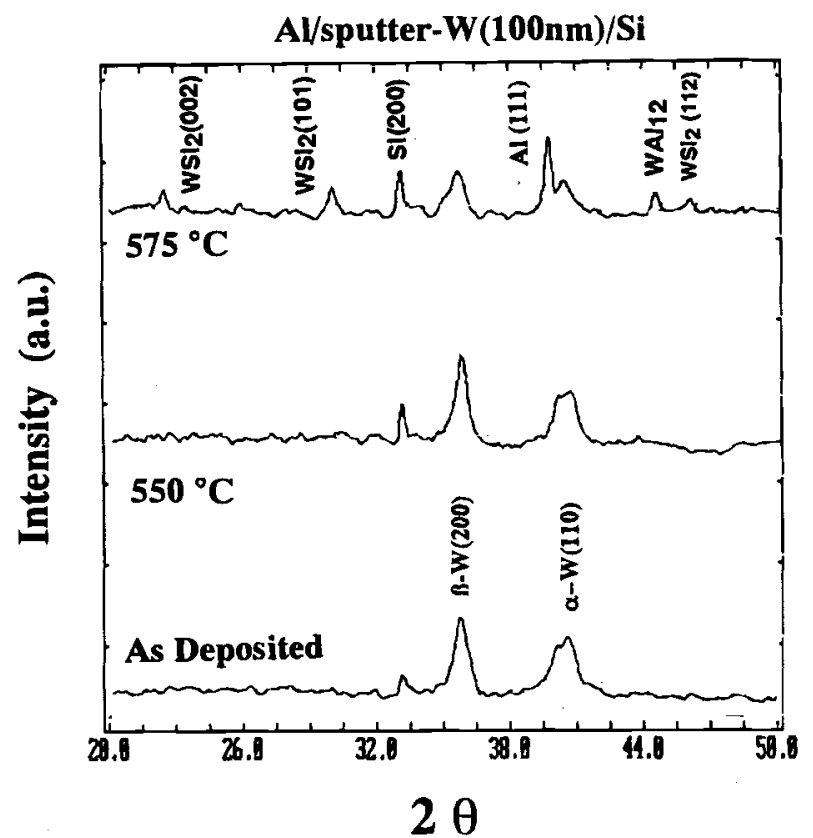

Fig. 4. XRD spectra of $A / /$ sputter-W $(100 \mathrm{~nm}) / \mathrm{Si}$ sample before and after thermal annealing.

increased with sputtering time of ion milling (Fig. $7 a_{1}$ ); in contrast, the $O_{1 s}$ peak for the Al/CVD-W/Si samples $($ B.E. $=532.6 \mathrm{eV})$ decayed with sputtering time $\left(\right.$ Fig. $\left.7 \mathrm{~b}_{1}\right)$. Apparently, there is an oxygen accumulation at the Al/sputter-W interface, but not at the Al/CVD-W interface. The presence of oxygen in the sputter-W film will retard the formation of $\mathrm{WAl}_{12}$ leading to improved thermal stability of the $\mathrm{Al} /$ sputter-W interface. For the $\mathrm{W}$ signal, the XPS analysis showed that both the $\mathrm{W}_{4} \mathrm{f}_{7 / 2}$ peak (B.E. $=$ $30.981 \mathrm{eV}$ for CVD-W and B.E. = $31.092 \mathrm{eV}$ for sputter-W) and $\mathrm{W}_{4} \mathrm{f}_{5 / 2}$ peak (B.E. $=33.216 \mathrm{eV}$ for both samples) increased with sputtering time until the $W$ surface was reached (Fig. $7 \mathrm{a}_{2}$ and Fig. $7 \mathrm{~b}_{2}$ ). For the Al signal, a doublet $\mathrm{Al}_{2 \mathrm{p}}$ signal was observed for the $\mathrm{Al} /$ sputter-W/Si sample; one of the doublets occurred at $72.75 \mathrm{eV}[\mathrm{Al}(1)]$ corresponding to the metallic $\mathrm{Al},{ }^{12}$ while the second one shifted $2.9 \mathrm{eV}$ toward higher energy $[\mathrm{Al}(2) ; \mathrm{B} . \mathrm{E} .=75.65 \mathrm{eV}]$ characterizing the aluminum oxide (Fig. $7 \mathrm{a}_{3}$ ). Various shifts, between 2.5 and $3.5 \mathrm{eV}$ for the B.E. values of the $\mathrm{Al}_{2 \mathrm{p}}$ peaks, have been reported for the aluminum oxide depending on the structure of the films ${ }^{13}$ For the Al/CVD-W/Si sample, only one metallic $\mathrm{Al}_{2 \mathrm{p}}$ signal $[\mathrm{Al}(1) ; \mathrm{B} . \mathrm{E} .=72.43 \mathrm{eV}]$ was detected (Fig. $7 \mathrm{~b}_{3}$ ).

The SIMS depth profiles were used to reveal the elemental distributions in multilayered structures. Figure 8 shows the SIMS depth profiles of the four different $\mathrm{Al} / \mathrm{W} / \mathrm{Si}$ structures before and after the $550^{\circ} \mathrm{C}$ anneal. The interdiffuion of $\mathrm{Al}$ and $\mathrm{Si}$ led to severe degradation of the $\mathrm{Al} / \mathrm{CVD}-\mathrm{W}(100 \mathrm{~nm}) / \mathrm{Si}$ structure after the $550^{\circ} \mathrm{C}$ anneal, as shown in Fig. 8a, where the $\mathrm{W}$ layer was transformed almost entirely into $\mathrm{WAl}_{12}$ and has lost its barrier capability against the Al diffusion. The barrier property of the sputter-W is much better than that of the CVD-W, as shown in Fig. 8b; this is presumbly due to high oxygen content in the sputter-W film which retarded the formation of $\mathrm{WAl}_{12}$. For the $\mathrm{Al} / \mathrm{CVD}-\mathrm{W}(300 \mathrm{~nm}) / \mathrm{Si}$ sample, interdiffusion of $\mathrm{Al}$ and $\mathrm{W}$ still occurred at the $\mathrm{Al} / \mathrm{W}$ interface after $550^{\circ} \mathrm{C}$ annealing, but the W/Si interface remained nearly unchanged, as shown in Fig. 8c. The insertion of a TiN layer between the $\mathrm{Al}$ and $\mathrm{W}$ layers was effective in keeping the $\mathrm{W}$ and $\mathrm{Si}$ depth profiles almost unchanged, while the Al diffused only slightly into the $W$ film, as shown in Fig. 8d. It has been reported that the composition of the reactively sputter deposited TiN is off 


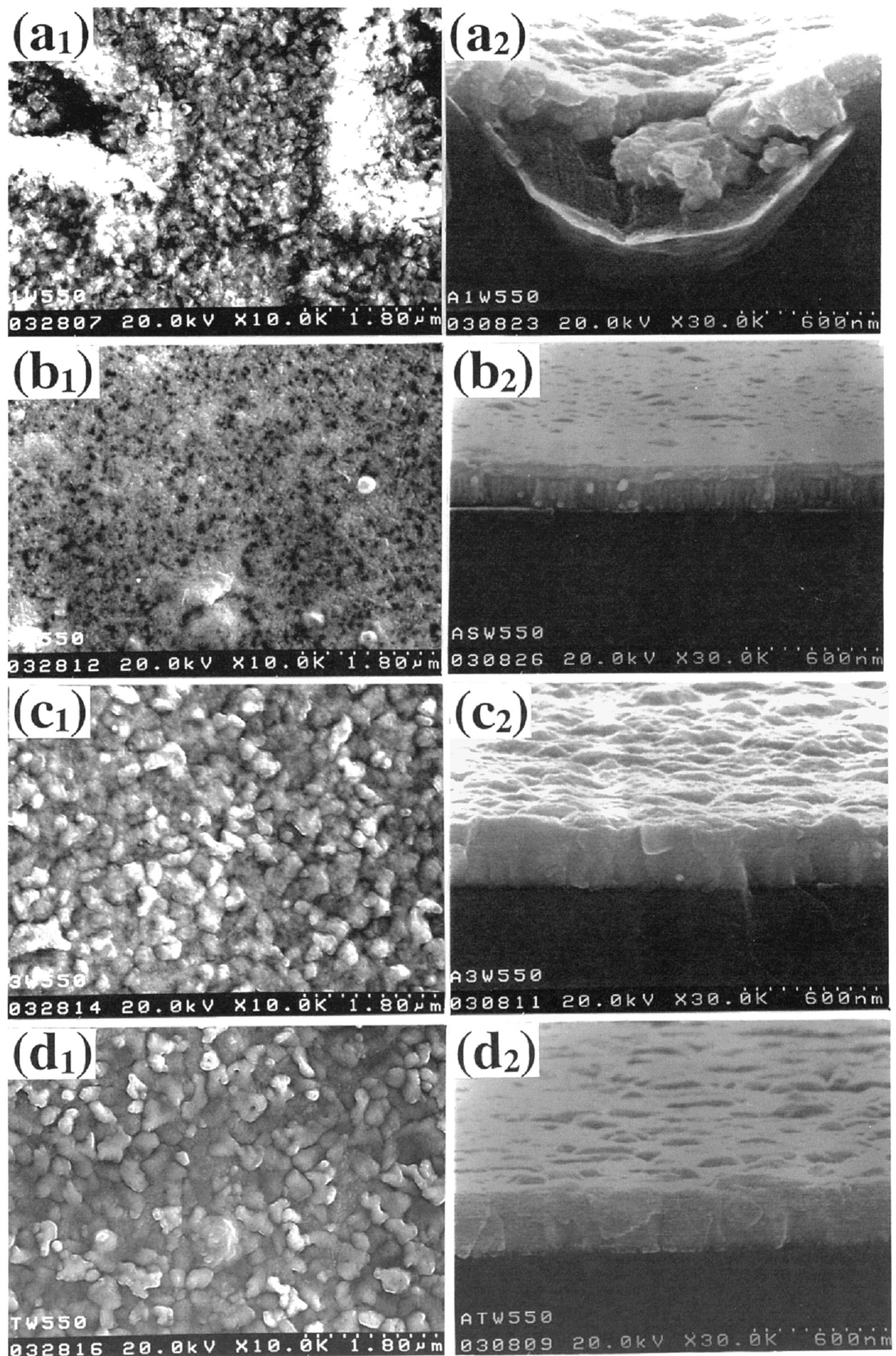

Fig. 5. Top view (left) and cross section (right) SEM micrographs of $\left(a_{1}, a_{2}\right) A l / C V D-W(100 \mathrm{~nm}) / \mathrm{Si}_{1}\left(\mathrm{~b}_{1}, \mathrm{~b}_{2}\right) \mathrm{Al} / \mathrm{sputter}-\mathrm{W}(100 \mathrm{~nm}) / \mathrm{Si},\left(c_{1}\right.$, $\left.c_{2}\right) \mathrm{Al} / \mathrm{CVD}-\mathrm{W}(300 \mathrm{~nm},) / \mathrm{Si}$, and $\left(d_{1}, \mathrm{~d}_{2}\right) \mathrm{Al} / \mathrm{TiN}(40 \mathrm{~nm}) / \mathrm{CVD}-\mathrm{W}(300 \mathrm{~nm}) / \mathrm{Si}$ samples after $550^{\circ} \mathrm{C}$ anneal for $30 \mathrm{~min}$. 


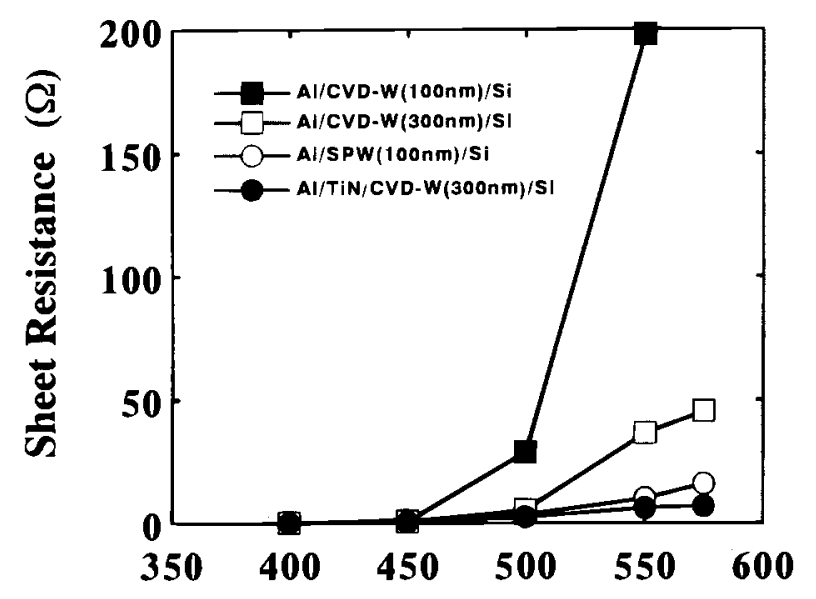

\section{Annealing Temperature $\left({ }^{\circ} \mathrm{C}\right)$}

Fig. 6. Sheet resistance vs. annealing temperature for various diode structures.

stoichiometric, ${ }^{14}$ thus $\mathrm{Al}$ could reach the $\mathrm{W}$ surface along the grain boundary of the TiN layer. Another possible cause of degradation in the $\mathrm{Al} / \mathrm{TiN} / \mathrm{W} / \mathrm{Si}$ structure is due to
AlN or $\mathrm{TiAl}_{3}{ }^{15}$ formation after $550^{\circ} \mathrm{C}$ annealing. Therefore, it is important to deposit the TiN film with the minimum amount of excess $\mathrm{Ti}^{14}$ or with N-rich TiN. ${ }^{16}$

Contact resistivities of the Al/TiN/CVD-W/p $\mathrm{p}^{+} \mathrm{n}$ diodes were found to be slightly higher than those of the Al/CVD$\mathrm{W} / \mathrm{p}^{+} \mathrm{n}$ diodes, which is around $5 \times 10^{-7} \Omega \mathrm{cm}^{2}$. For the $\mathrm{Al} / \mathrm{sputter}-\mathrm{W} / \mathrm{p}^{+} \mathrm{n}$ diodes, contact resistivity larger than $10^{-6} \Omega \mathrm{cm}^{2}$ was obtained, presumably because native oxide on the Si substrate was not completely removed prior to the sputter-W deposition. With annealing at elevated temperatures, thermal stability of contact resistance for the $\mathrm{Al} / \mathrm{CVD}-\mathrm{W} / \mathrm{p}^{+} \mathrm{n}$ diodes depends on the thickness of $\mathrm{W}$ film. Figure 9 shows the increase of contact resistance as a function of annealing temperature. With a CVD-W layer of 300 $\mathrm{nm}$ thickness, the contact resistance could remain stable only up to $500^{\circ} \mathrm{C}$. However, with the insertion of a $40 \mathrm{~nm}$ TiN layer, contact resistance of the Al/TiN/CVD-W (300 $\mathrm{nm}) / \mathrm{p}^{+} \mathrm{n}$ diode was not changed up to $575^{\circ} \mathrm{C}$. The degradation behavior of the contact resistance is similar to that of the sheet resistance. The TiN layer efficiently suppressed the formation of $\mathrm{WAl}_{12}$ and thus improved the thermal stability of the W-contacted Al/TiN/CVD-W/p $/ \mathrm{p}^{+} \mathrm{n}$ diode.

\section{Conclusion}

Thermal stability of the W contacted $p^{+} n$ junction diodes was investigated. Reaction of $\mathrm{Al}$ and $\mathrm{CVD}-\mathrm{W}$ at ele-

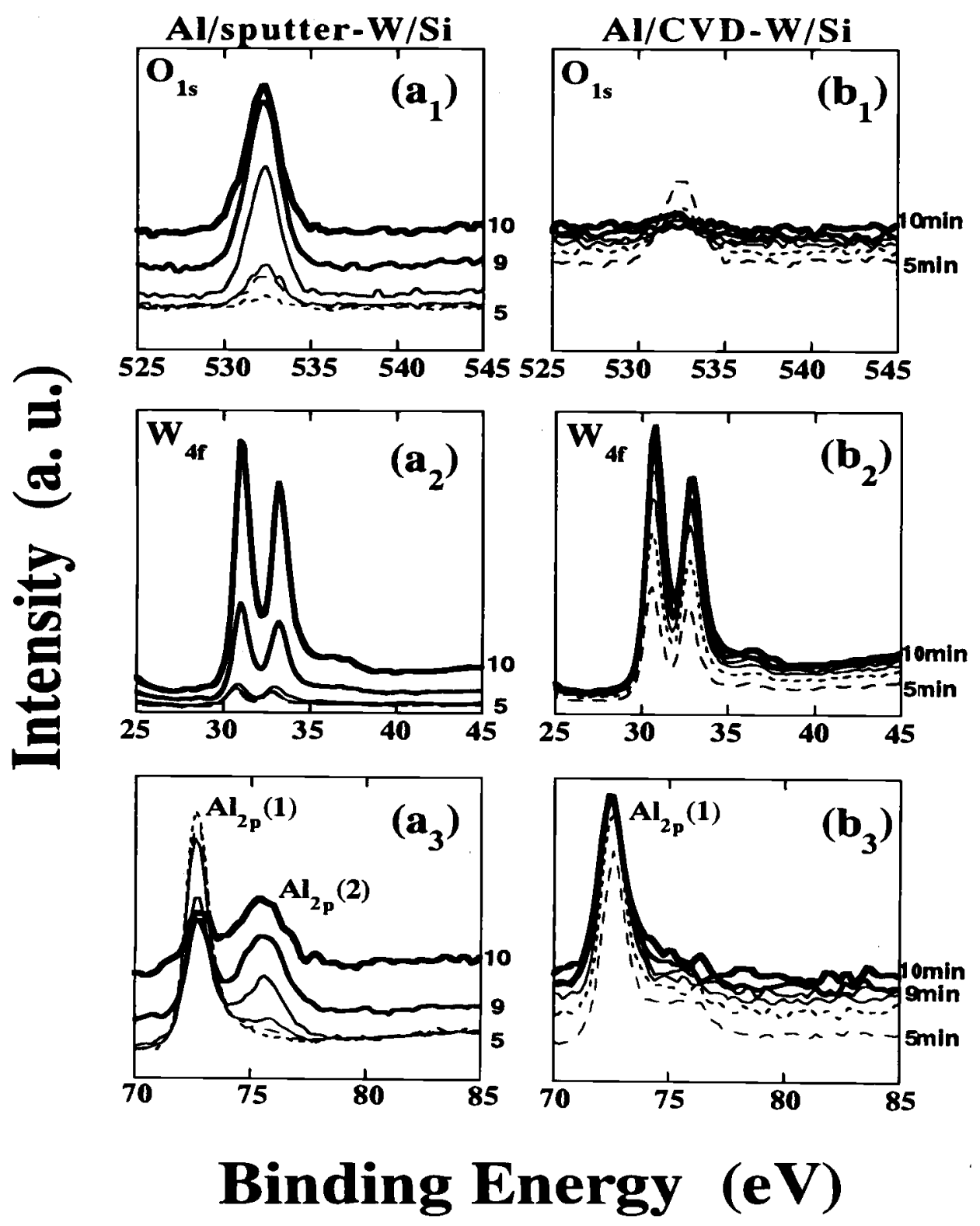

Fig. 7. XPS spectra of (a) Al/sputter-W/Si and (b) Al/CVD$\mathrm{W} / \mathrm{Si}$ multilayers offer $550^{\circ} \mathrm{C}$ annealing. The spultering times are indicated on the edge of each illustration. 


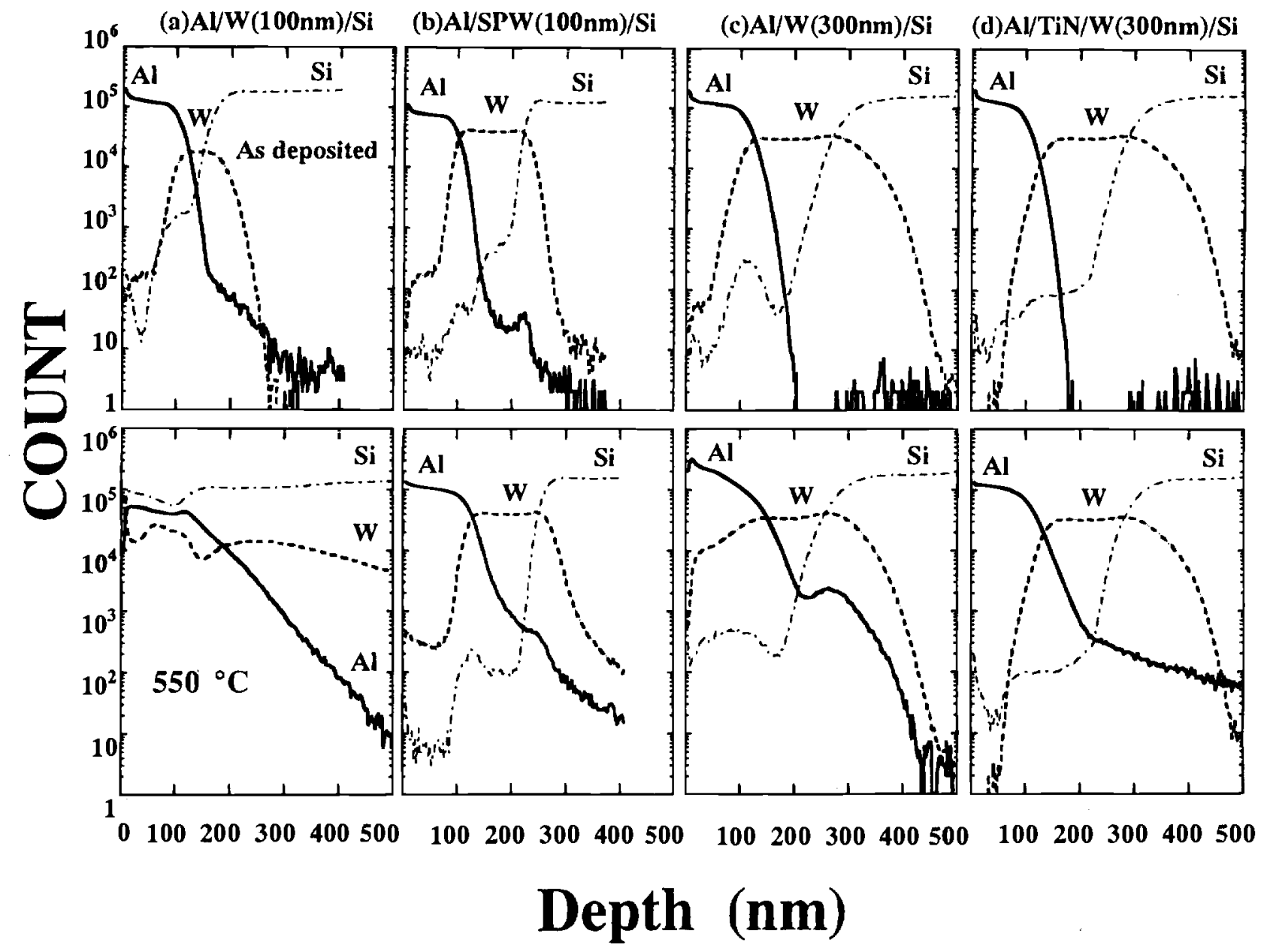

Fig. 8. SIMS depth profiles of (a) Al/CVD-W $(100 \mathrm{~nm}) / \mathrm{Si}$, (b) Al/sputter-W (100 nm)/Si, (c) Al/CVD-W (300 nm)/Si, and (d) Al/TiN $(40 \mathrm{~nm}) / \mathrm{CVD}-W(300 \mathrm{~nm}) / \mathrm{Si}$ samples before and after thermal annealing.

vated temperature leads to the formation of $\mathrm{WAl}_{12}$, and the barrier capability of CVD-W film against $\mathrm{Al}$ diffusion into the Si substrate was dependent on the consumption of W. The barrier effect of sputter-W film is superior to that of CVD-W film owing to the fact that the sputter-W contains a higher content of oxygen, which retarded the formation of $\mathrm{WAl}_{12}$ during the high-temperature anneal. The junction

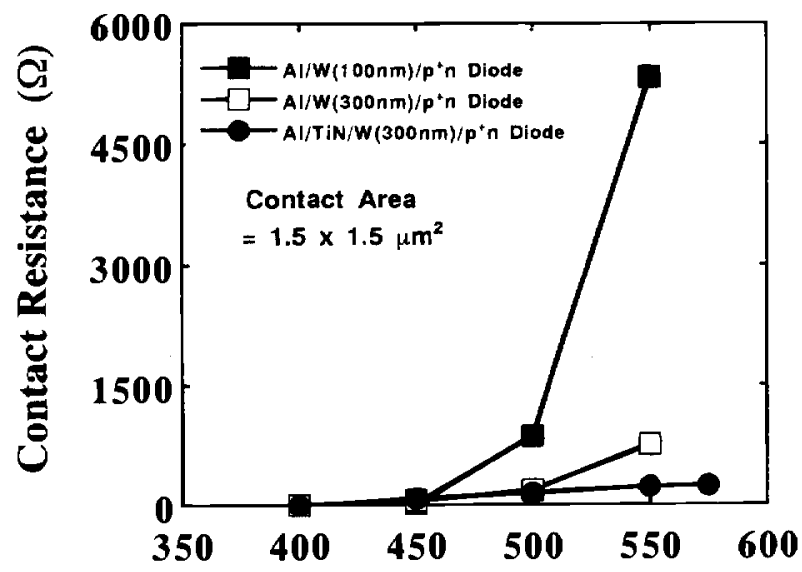

Annealing Temperature $\left({ }^{\circ} \mathrm{C}\right)$

Fig. 9. Contact resistance vs. annealing temperature for various diode structures. degradation occurred on the $550^{\circ} \mathrm{C} / 30$ min annealed $\mathrm{Al} /$ sputter-W $(100 \mathrm{~nm}) / \mathrm{p}^{+} \mathrm{n}$ diodes is presumably due to $\mathrm{Al}$ diffusion through the grain boundary of sputter-W film, which has a columnar $\mathrm{W}$ structure. The insertion of a thin TiN barrier layer between the $\mathrm{Al}$ and CVD-W film suppressed the formation of $\mathrm{WAl}_{12}$ and thus improved the thermal stability of the $\mathrm{W}$ contacted $\mathrm{p}^{+} \mathrm{n}$ diodes.

\section{Acknowledgments}

This work was supported by National Science Council, ROC under Contract No. NSC84-2622-E009-007-1.

Manuscript submitted Oct. 27, 1995; revised manuscript received April 6, 1996

National Chiao Tung University assisted in meeting the publication costs of this article.

\section{REFERENCES}

1. N. E. Miller and I. Beinglass, Solid State Technol., 23, $79(1980)$

2. T. Hara, S. Enomoto, N. Ohtsuka, and S. Shima, Jpn. J. Appl. Phys., 24, 828 (1985)

3. L. Gutai, M. Delfino, and J. M. De Blasi, Mater Res. Soc. Symp. Proc., 178, 265 (1987)

4. R. V. Levy, M. L. Green, P. K. Gallagher, and Y. S. Ali, This Journal, 133, 1905 (1986).

5. Y. Shioya, M. Maeda, and K. Yanaida, J. Vac. Sci Technol., B4, 1175 (1986).

6. M. Hammar, S. L. Zhang, R. Buchta, and T. Johansson, Thin Solid Films, 185, 9 (1990).

7. Y. Pauleau, F. C. Dassapa, P. Lami, J. C. Oberlin, and F. Romagna, J, Vac. Sci. Technol, B6, 817 (1988). 
8. H. H. Hoang, Proc. IRPS, p. 273 (1988).

9. P. H. Chang and H. M. Chen, J. Appl. Phys., 72, 2739 (1992).

10. B. W. Shen and G. C. Smith, J. Vac. Sci. Technol, B4, 1369 (1986).

11. Y. Harada, H. Onoda, and S. Madokoro, Mater. Res. Soc. Symp. Proc., 181, 615 (1990)

12. C. Jimenez, M. Fernandez, J. M. Albella, and J. M. Duart, Appl. Surf. Sci., 70, 475 (1993).
13. J. Avila and J. L. Sacedon, J. Vac. Sci. Technol, A10, 2698 (1992).

14. K. Hinode and Y. Homma, Proc. IRPS, p. 25 (1990).

15. Y. Inoue, $S$. I. Tanimoto, $K$. Tsujimura, T. Yamashita Y. Ibara, Y. Yamashita, and K. Yoneda, This Journal, 141, 1056 (1994).

16. S. Q. Wang, I. Raaijmakers, B. J. Burrow, S. Suthar S. Redkar, and K. B. Kim, J. Appl. Phys., 68, 5176 (1990).

\title{
Orientation Control of Chemical Vapor Deposition TiN Film for Barrier Applications
}

\author{
R. W. Fiordalice, R. I. Hegde, and H. Kawasaki \\ Motorola, Incorporated, Advanced Products Research and Development Laboratory, Austin, Texas 78721, USA
}

\section{ABSTRACT}

A chemical vapor deposition (CVD) TiN film with preferred $<111>$ crystal orientation was developed using an in situ two-step process scheme. A thin CVD TiN layer is deposited first under low $\mathrm{TiCl}_{4}$ partial pressure. This layer has poor step coverage, but acts as a crystallographic seed layer for the subsequent CVD TiN layer deposited under high TiCl ${ }_{4}$ partial pressure. This layer, deposited sequentially without breaking vacuum, shows a TiN $<111>$ preferred orientation when deposited under these conditions and provides excellent step coverage. This CVD TiN layer "stack" has shown both excellent diffusion barrier properties to CVD $\mathrm{Cu}$, and improved electromigration reliability relative to conventional CVD TiN using $\mathrm{TiCl}_{4} / \mathrm{NH}_{3}$ chemistry.

\section{Introduction}

The limitations of sputtered barriers and contacting layers have become increasingly apparent as contact feature size continues to scale down. ${ }^{1-7}$ In response, much effort has been put into the development of barriers and contacting layers that are deposited by chemical vapor deposition (CVD). Specifically, CVD TiN has been integrated electrically into $0.5 \mu \mathrm{m}$ static random access memory (SRAM) devices at the contact level. ${ }^{2}$ CVD TiN films from $\mathrm{TiCl}_{4} / \mathrm{NH}_{3}$ chemistry have been shown to be excellent diffusion barriers between aluminum and silicon, as well as nucleation layers for CVD tungsten. ${ }^{1}$ However, the preferred $<200\rangle$ crystal orientation of CVD TiN has posed a problem. The $<200>$ orientation of the TiN has been shown to translate to the overlying aluminum interconnect, enhancing the $<200\rangle \mathrm{Al}$ feature. It has been demonstrated that an enhanced $\langle 200\rangle$ orientation in aluminum interconnects portends poor electromigration performance. Therefore, the underlying $<200>$ CVD TiN film degrades electromigration performance of the overlying aluminum interconnect by translating $<200\rangle$ texture.

In this paper a method to control the crystal orientation of the CVD TiN layer to produce a preferred $<111>$ orientation is discussed. Although the $<111>$ orientation of CVD TiN from $\mathrm{TiCl}_{4} / \mathrm{NH}_{3}$ chemistry has been demonstrated in the past, the resulting films showed poor step coverage. ${ }^{5}$ Through the in situ layering of films deposited under two distinct process conditions, we show that it is possible to retain the conformality of the film, while at the same time producing a $<111>$ preferred crystal orientation. Further it was found that this $<111>$ orientation translates to the overlying aluminum interconnects, enhancing the $\mathrm{Al}$ $<111>$ feature. The improvement of the aluminum texture leads to an appreciable increase in the interconnect median time to failure (MTTF) under electromigration stress conditions. ${ }^{8}$ The other favorable qualities of CVD TiN, such as diffusion barrier and nucleation layer characteristics, are retained under these process conditions.

\section{Experimental}

The CVD TiN depositions were carried out in a singlewafer cold wall reactor as described elsewhere. ${ }^{1}$ The system is a load-locked, single-wafer reactor chamber with a linear cassette to cassette wafer transport. The substrate is radiantly heated from the back side. A thermocouple in contact with the center of the substrate's back side provides closed loop temperature control within $\pm 1 \%$ of the set point.

The CVD TiN films were characterized by Auger electron spectroscopy (AES), and scanning electron microscopy (SEM). The crystalline orientation of the CVD TiN films processed under various conditions and that of the overlying Al films were determined using the $x$-ray diffraction (XRD) technique. The $\mathbf{x}$-ray source was a Cu $\mathrm{K}_{\alpha}$ operated at $45 \mathrm{kV}$ and $40 \mathrm{~mA}$. Both the glancing angle and $\theta / 2 \theta$ diffraction methods were used for the crystalline determination. The latter method provides a quick method for determining the crystalline orientation and for checking the film texture. The oxygen, chlorine, and carbon contents were determined from AES. The sheet resistance of the films was measured with a Prometrix Omni map four-point probe (49 points/wafer). The film resistivities were derived from the sheet resistance and the film thickness in the usual manner. The film thicknesses were measured by $x$-ray fluorescence, calibrated by both cross-sectional transmission electron microscopy (XTEM) and Rutherford backscattering (RBS)

\section{Results and Discussion}

Film characteristics.-Traditionally, CVD TiN from $\mathrm{TiCl}_{3} / \mathrm{NH}_{3}$ chemistry has been deposited with $\mathrm{TiCl}_{4}$ partial pressures in the $1.0_{4}$ to 15.0 mTorr range. TiN films deposited under this regime and at elevated temperatures $\left(>550^{\circ} \mathrm{C}\right)$ have shown excellent step coverage, near-bulk film density, low chlorine and oxygen concentrations, and a $<200>$ preferred crystal orientation. ${ }^{1,4}$ Recent work has shown that CVD TiN films deposited at much lower $\mathrm{TiCl}_{4}$ partial pressure show very different film characteristics. ${ }^{5}$ Films deposited at these low $\mathrm{TiCl}_{4}$ partial pressures have shown a TiN $<111>$ preferred orientation, higher oxygen concentrations, and lower chlorine concentrations. However, these films also demonstrate poor step coverage. By the in situ layering of film deposited at both high and low $\mathrm{TiCl}_{4}$ partial pressures, a CVD TiN film that is both conformal and $<111>$ preferentially oriented has been developed. 